\title{
LA NECESARIA ERRADICACIÓN DE LA ESTERILIZACIÓN NO CONSENTIDA DE MUJERES CON DISCAPACIDAD DESDE EL MARCO DE LOS DERECHOS HUMANOS'
}

\author{
The need to end forced sterilisation of women with \\ disabilities from the perspective of human rigths \\ CELIA PRADOS GARCÍA \\ Universidad de Córdoba \\ cprados@uco.es
}

Cómo citar/Citation

Prados García, C. (2021).

La necesaria erradicación de la esterilización no consentida de mujeres con discapacidad desde el marco de los derechos humanos.

IgualdadES, 5, 371-399.

doi:https://doi.org/10.18042/cepc/lgdES.5.03

(Recepción: 13/07/2021; aceptación tras revisión: 26/10/2021; publicación: 20/12/2021)

\section{Resumen}

Con este trabajo se pretende analizar la efectividad de la Ley Orgánica 2/2020, que persigue la erradicación de la esterilización forzada o no consentida de personas con discapacidad, en el contexto de adaptación y modificación del ordenamiento español a los postulados de la Convención sobre los Derechos de las Personas con Discapacidad. La Ley deroga el art. 156 del Código Penal, que establecía que no sería punible la esterilización acordada por el órgano judicial en el caso de personas que, de

1 Este artículo ha sido realizado en el marco del proyecto de investigación RTI2018100669-b-100 GEN-DER: «Generando una interpretación del Derecho en clave de igualdad de género", enmarcado en el Programa Estatal de $\mathrm{I}+\mathrm{D}+\mathrm{i}$ Orientada a los Retos de la Sociedad, Ministerio de Ciencia e Innovación (2019-2021). 
forma permanente, no pudieran prestar consentimiento. Sin embargo, la erradicación de este tipo de prácticas solo será real y efectiva cuando se garantice un consentimiento accesible y debidamente informado a las mujeres con discapacidad que opten por este método anticonceptivo.

\section{Palabras clave}

Esterilización; discapacidad; consentimiento informado; derechos sexuales y reproductivos.

\section{Abstract}

This work analyses the effectiveness of Organic Law $2 / 2020$, whose purpose is to end non-consensual or forced sterilisation of persons with disabilities in the context of adapting and amending Spanish law to the provisions of the Convention on the Rights of Persons with Disabilities. The law abolishes Article 156 of the Criminal Code, which provided that sterilisation authorised by a court is not punishable in the case of permanently incapacitated persons who are unable to consent. However, these types of practice will only end when it is guaranteed that women with disabilities who opt for this contraceptive method have been given access to and have given their duly informed consent.

\section{Keywords}

Sterilisation; disability; informed consent; sexual and reproductive rights. 


\section{SUMARIO}

I. EL NUEVO TRATAMIENTO JURÍDICO DE LA DISCAPACIDAD: 1. Los derechos sexuales y reproductivos de las mujeres con discapacidad. 2. La esterilización forzada o no consentida desde un enfoque de género. II. ADAPTACIÓN DE LA NORMATIVA REGULADORA DEL CONSENTIMIENTO INFORMADO A LA CONVENCIÓN: 1. Accesibilidad a la información del consentimiento informado. 2. Adaptación del consentimiento por representación. III. CONCLUSIONES. BIBLIOGRAFíA.

\section{EL NUEVO TRATAMIENTO JURÍDICO DE LA DISCAPACIDAD}

La Convención Internacional sobre los Derechos de las Personas con Discapacidad marcó un hito al abordar la discapacidad desde un nuevo enfoque, el de los derechos humanos. El tratado fue ratificado por España a través del Instrumento de Ratificación de 23 de noviembre de 2007 y entró en vigor el 3 de mayo de 2008. Tal y como se desprende de su art. 1, la Convención tiene como propósito proteger y asegurar el goce de los derechos humanos y libertades fundamentales de todas las personas con discapacidad, así como promover el respeto de su dignidad inherente. La Organización Mundial de la Salud (OMS) insiste en esta cuestión, pues la discapacidad es una cuestión de derechos humanos en la que adultos, adolescentes y niños con discapacidad sufren estigmatización, discriminación y desigualdad. Con cierta frecuencia las personas con discapacidad sufren múltiples violaciones de sus derechos, incluida la dignidad, a través de actos de violencia, abuso, prejuicio y falta de respeto que tienen como causa la discapacidad ${ }^{2}$.

La Convención evidencia la superación del modelo médico rehabilitador, propio de legislaciones obsoletas que identificaban la discapacidad con la enfermedad del sujeto que la padecía. La razón de esta asimilación tuvo su origen en la Clasificación de las Deficiencias, Discapacidades y Minusvalías (DIDDM) publicada inicialmente por la OMS con carácter

2 World Health Organization (2015). Who Global Disability Action Plan 2014-2021. Better Health for all people with disability. Disponible en: https://bit.ly/3EDVb7q (consultado el 20 de noviembre de 2020). 
experimental en $1980^{3}$. En dicha clasificación la discapacidad era un asunto de salud, delimitado por especialistas en medicina y psiquiatría, y desde la terapia y la rehabilitación fue plasmada y desarrollada en las normas jurídicas. Por el contrario, el modelo social entiende la discapacidad como un problema en el que las restricciones personales no tienen su origen en la deficiencia, sino en la propia sociedad que no tiene en cuenta la situación de estas personas, generando barreras que las excluyen y discriminan. En este sentido, la discapacidad vendría a ser «una construcción relacional entre la sociedad y un sujeto (individual o colectivo)» (Brogna, 2006), frente a la concepción de la discapacidad como un hecho exclusivamente individual, o afección fisiológica, que una persona padece y debe ser curada (Vázquez, 2008). Este nuevo planteamiento pone su enfoque en un entorno social que responde a un patrón de individuo estándar y pone en evidencia la necesidad de una sociedad inclusiva. Sin embargo, el Informe de derechos humanos y discapacidad en España (2020) muestra que aún está presente el modelo médico rehabilitador, pues es muy frecuente la acusada tendencia, por parte de los profesionales de la salud, a vincular cualquier dolencia a la discapacidad. Por ello, es fundamental abordar la discapacidad desde el enfoque social, en el que las personas con discapacidad sean reconocidas como sujetos de derecho, en lugar de quedar reducidas a "portadoras de deficiencias que han de ser subsanadas» (Cermi, 2021).

En aplicación del modelo social se debe garantizar el ejercicio de la capacidad jurídica de todas las personas con discapacidad, cuya efectividad discurre por el cumplimiento de la voluntad, preferencias y deseos de las personas con discapacidad, evitándose, en la medida de lo posible, el modelo de sustitución de la voluntad, que conlleva el consentimiento por representación. La Convención hace especial hincapié en la autonomía y libertad de las personas para la toma de decisiones. Así lo determina en su art. 3, al establecer que la elección de los planes de vida no puede verse restringida por la discapacidad. En el art. 12.2 se establece la presunción de capacidad a favor de las personas con discapacidad, lo que impide que «las deficiencias puedan por sí mismas constituir excepciones justificadas a esta presunción general de plena capacidad jurídica» (López Barba, 2020:119). El precepto insta a los Estados

3 Afortunadamente, estos criterios fueron revisados por la Clasificación internacional del funcionamiento, de la discapacidad y de la salud, conocida como ClF, en 2001. Esta nueva clasificación tiene como objetivo proporcionar un lenguaje unificado y estandarizado que sirva para describir la salud y los estados relacionados con la misma. En esta ocasión lo hace desde un modelo multidimensional complejo estructurado en torno dos categorías: funcionamiento y discapacidad, y, factores ambientales. 
parte a reconocer la capacidad para obligarse de todas las personas mayores de edad, sin distinción alguna por razón de discapacidad. Y en el apartado tercero ordena a los Estados a adoptar las medidas de apoyo necesarias para garantizar el ejercicio efectivo de la capacidad jurídica. En aplicación de este modelo social de la discapacidad, las personas no deben ser representadas ni su voluntad sustituida. De hecho, cuando la voluntad de la persona no puede ser debidamente expresada, debe reconstruirse su voluntad teniendo en cuenta su trayectoria vital.

En lo que se refiere al art. 23 de la Convención, los Estados deben tomar medidas para poner fin a la discriminación de las personas con discapacidad en las cuestiones relacionadas con la familia. Para ello se reconoce el derecho a contraer matrimonio, a fundar una familia, a tener acceso a la información y educación sobre reproducción y planificación familiar, así como a mantener la fertilidad en igualdad de condiciones. De esta forma, las personas con discapacidad pueden elegir ser padres y madres de forma biológica, acceder a la maternidad y paternidad a través de la adopción o de técnicas de reproducción asistida.

En su preámbulo, la Convención recuerda otros tratados internacionales ${ }^{4}$, entre ellos el "Convenio del Consejo de Europa sobre prevención y lucha contra la violencia contra las mujeres y la violencia doméstica», que prohíbe expresamente las esterilizaciones forzadas. El art. 39 del denominado Convenio de Estambul tipifica como delito la práctica de cualquier «intervención quirúrgica que tenga por objeto poner fin a la capacidad de una mujer de reproducirse de modo natural sin su consentimiento previo e informado o sin su entendimiento del procedimiento». Además, establece que "nadie podrá ser sometido a tortura ni a penas o tratos inhumanos o degradantes» y regula el derecho de toda persona al respeto a su vida privada y familiar, estableciendo que «no podrá haber injerencia de la autoridad pública en el ejercicio de este derecho, sino en tanto en cuanto esta injerencia esté prevista por la ley y constituya una medida que, en una sociedad democrática, sea necesaria para la seguridad nacional, [...] la protección de la salud o de la moral, o la protección de los derechos y libertades de los demás».

4 Pacto Internacional de Derechos Económicos, Sociales y Culturales, el Pacto Internacional de Derechos Civiles y Políticos, la Convención Internacional sobre la Eliminación de todas las Formas de Discriminación Racial, la Convención sobre la Eliminación de Todas las Formas de Discriminación contra la Mujer, la Convención contra la Tortura y Otros Tratos o Penas Crueles, Inhumanos o Degradantes, la Convención sobre los Derechos del Niño y la Convención Internacional sobre la Protección de los Derechos de Todos los Trabajadores Migratorios y de sus Familiares. 
Sin embargo, a pesar de la ratificación por parte del Estado español de dichos tratados internacionales, se ha practicado la esterilización no consentida de mujeres y niñas con discapacidad intelectual o psicosocial ${ }^{5}$. Dicha práctica ha encontrado cobertura legal en el párrafo segundo del art. 156 de la Ley Orgánica 10/1995, de 23 de noviembre, del Código Penal, que permitía la esterilización acordada por el órgano judicial en el caso de "personas con discapacidad incapacitadas judicialmente». Dicha actuación podía tener cabida siempre que se tratase de supuestos excepcionales en los que se produjera un "grave conflicto de bienes jurídicos protegidos, a fin de salvaguardar el mayor interés del afectado, todo ello con arreglo a lo establecido en la legislación civil». La exención prevista en el referido art., que no hacía punible la esterilización acordada por órgano judicial, ha permitido la esterilización de miles de personas con discapacidad. Esto ha constituido una clara vulneración de los derechos humanos por atentar directamente contra los arts. 12, 15 y 23 de la Convención (reguladores de la capacidad jurídica, la protección contra la tortura y otros tratos o penas crueles, inhumanos o degradantes, así como del derecho a fundar una familia) y del Convenio de Estambul.

No obstante, desde la ratificación de la Convención de las Naciones Unidas, el Estado español ha ido armonizando la legislación interna a los postulados del tratado, dando muestra de la evolución hacia un nuevo tratamiento jurídico de la discapacidad. En este contexto, el pasado 18 de diciembre de 2020 entró en vigor la Ley Orgánica 2/2020, de 16 de diciembre, para la erradicación de la esterilización forzada o no consentida de personas con discapacidad incapacitadas judicialmente. La norma deroga el párrafo segundo del art. 156 del Código Penal, que permitía la esterilización acordada por órgano judicial en el caso de personas con discapacidad cuya capacidad había sido modificada judicialmente. También en el ámbito civil se han llevado a cabo importantes avances. La ley 26/2011, de 1 de agosto, que incorporó importantes novedades, dio un plazo de un año al Gobierno para que remitiera a las Cortes Generales un proyecto de ley de adaptación normativa del ordenamiento jurídico para dar cumplimiento al art. 12 CDPD. Sin embargo, la reforma del Código Civil ha venido de la mano de la ley 8/2021, de 2 de junio, por la que se reforma la legislación civil y procesal para el apoyo a las personas

5 En cuanto a las cifras oficiales, se han podido consultar los datos publicados por la Fundación CERMI en un informe de 2018, pero estos comprenden las esterilizaciones no consentidas practicadas entre 2005 y 2016. Sin embargo, aunque se aprecia cierta tendencia a la baja, se advierte falta de transparencia en los datos publicados por el Consejo General del Poder Judicial (CGPJ), lo que impide conocer con detalle la situación real de esta problemática en nuestro país (Casas, 2021). 
con discapacidad en el ejercicio de su capacidad jurídica. La ley es resultado de un complejo y extenso proceso de elaboración, cuyo objetivo central es el derecho de las personas con discapacidad a tomar sus propias decisiones. La reforma supone un cambio radical, transversal y complejo del concepto de capacidad jurídica (García Rubio, 2021). En consonancia con el espíritu de la Convención, la ley reemplaza la sustitución en la toma de decisiones por un sistema de apoyos con un único criterio de actuación: el respeto a la voluntad, deseos y preferencias de las personas con discapacidad. Este derecho a la toma de decisiones se pone de manifiesto tanto por la prioridad de las medidas de apoyo voluntarias, como por la necesidad de que quien preste el apoyo respete la voluntad de la persona con discapacidad (art. 249 CC). De hecho, la ley no contempla la actuación en mejor interés de la persona y restringe los supuestos en los que se permite la sustitución en la toma de decisiones (art. 264 CC), tanto en los apoyos informales como en los formales de naturaleza judicial (curatela y defensor judicial). Un sector de la doctrina sostiene que del art. 249 CC se derivan dos consecuencias fundamentales (García Rubio, 2021). La primera es que el sistema de representación es una excepción a la regla general y no a la inversa. Y la segunda es que, en los casos de representación admitidos, el representante no podrá sustituir la voluntad del representado. Además, en el art. $278 \mathrm{CC}$ se establecen los actos en los que, sin perjuicio de lo que establezca la autorización judicial, el curador que ejerza funciones de representación necesita autorización judicial. En el primer párrafo se hace referencia expresa a los actos de trascendencia personal o familiar, con la salvedad de lo dispuesto legalmente en materia de consentimiento informado en el ámbito de la salud o en otras leyes especiales. Y es que queda pendiente la reforma legal en el ámbito sanitario, que deberá adaptarse a la nueva perspectiva social de la discapacidad, y, esperemos no se demore tanto como lo ha hecho la Ley $8 / 2021$.

En lo que se refiere al estado de la cuestión, Enmanuel Cartier (2019) sostiene que la presencia de los juristas en el campo de la discapacidad es relativamente reciente, en concreto en la esfera de la sexualidad y la capacidad. Según el autor, ello se debe a que se trata de un campo que ha sido estudiado principalmente desde el psicoanálisis, la psicología y la sociología. Sin embargo, en los últimos años se han incrementado los estudios sobre el tratamiento jurídico de la discapacidad. De los derechos sexuales y reproductivos, así como del derecho a fundar una familia de las mujeres con discapacidad, se han ocupado María Belén Andreu Martínez (2017), María Dolores Casas Planes (2021), María Dolores Palacios González (2019) y, en mayor profundidad, Cristina Guilarte Martín Calero, con un trabajo monográfico (2019). Han abordado el estudio de las esterilizaciones forzadas o no consentidas la Fundación CERMI (2018), Judith Solé Resina (2019) y muy recientemente Alba Paños 
Pérez (2021) e Inmaculada Vivas Tesón (2021). Desde una dimensión biojurídica destaca el estudio de Jimena Beatriz Manjón Rodríguez (2014). De la problemática de las esterilizaciones de las personas con discapacidad en Colombia se han ocupado Sara Hoyos Suárez y Jorge Mauricio Betancurt (2017), mientras que Ariadna Aguilera y Marian Gili Saldaña centraron su estudio en la República Eslovaca (2012). Sin embargo, la Ley Orgánica 2/2020, que persigue la erradicación de la esterilización forzada o no consentida de personas con discapacidad, es tan reciente que apenas se han publicado estudios sobre su aplicación y efectividad con la salvedad del estudio de Pastora García Álvarez (2021) desde el ámbito del Derecho Penal. Por ello, con este trabajo se pretende analizar el alcance de la ley, así como la necesaria reforma de la legislación civil en materia de consentimiento informado o por representación en el ámbito de la salud para que las esterilizaciones forzadas o no consentidas sean erradicadas de forma real y efectiva. Además, se hará especial hincapié en la accesibilidad a la información y en la formación que recibe el personal sanitario sobre esta materia como medida de prevención y sensibilización que, sin lugar a dudas, contribuirá a la erradicación de este tipo de violencia sexual.

\section{LOS DERECHOS SEXUALES Y REPRODUCTIVOS DE LAS MUJERES CON DISCAPACIDAD}

Con el propósito de profundizar en lo que representa la salud sexual y reproductiva, se ha acudido al Programa de Acción de la Conferencia Internacional sobre la Población y el Desarrollo celebrada en 1994ํ․ El Programa puso en valor la salud reproductiva como «un estado general de bienestar físico, mental y social», lejos de considerarla una «mera ausencia de enfermedades o dolencias» ${ }^{7}$. También constituye una pieza angular de la salud, el bienestar individual y la adopción responsable de decisiones sobre reproducción. Fruto de ello la salud reproductiva es considerada como «la capacidad de disfrutar de una vida sexual satisfactoria y sin riesgos y de procrear, y la libertad para decidir hacerlo o no hacerlo, cuándo y con qué frecuencia» ${ }^{8}$. Además, este reconocimiento lleva implícito el derecho de las personas a obtener información sobre

6 Programa de Acción aprobado en la Conferencia Internacional sobre la Población y el Desarrollo, del 5 al 13 de septiembre de 1994. Disponible en: https://bit.ly/31puhSk (consultado en febrero de 2021).

7 Organización Mundial de la Salud (2004). Estrategia de salud reproductiva para acelerar el avance hacia la consecución de los objetivos y las metas internacionales de desarrollo. Estrategia mundial adoptada por la 57. a Asamblea Mundial de la Salud, Ginebra. 8 Íd. 
planificación familiar que les permita tener el número de hijos deseados, así como determinar el correspondiente intervalo entre embarazos.

El desarrollo de esta definición amplia de salud incluye los métodos de salud y bienestar reproductivos, pero también los propios de la salud sexual que persigue el desarrollo de las relaciones personales, que nos aleja de la convencional atención que giraba en torno a la prevención de enfermedades de transmisión sexual y prevención en materia reproductiva. Además, en el ámbito de los derechos sexuales y reproductivos de las mujeres con discapacidad ha sido frecuente que se les infantilice y se les vea como seres asexuados y "carentes de potencias y necesidades sexuales», despojándolas de las características que han configurado su identidad femenina (Díaz, 2005). El Informe de derechos humanos y discapacidad alerta sobre que la reproducción sigue siendo un tema tabú "ya que en el imaginario colectivo una mujer con discapacidad sigue siendo considerada un cuerpo que debe ser controlado y su reproducción vigilada, ya que existe el riesgo de que las disfuncionalidades que supuestamente representa la presencia de una discapacidad se trasmitan como herencia» (CERMI, 2021).

Según lo expuesto, los derechos reproductivos abarcan derechos humanos que reconocen el derecho del individuo a decidir libre y responsablemente si quiere tener relaciones sexuales, hijos, el número de los mismos, optar al uso de anticonceptivos de emergencia, de acción breve o de acción prolongada o permanentes, así como a disponer de la información y de los medios necesarios para garantizar una salud sexual y reproductiva plena ${ }^{9}$. Así se puede afirmar que las personas con discapacidad han dejado de ser consideradas únicamente destinatarias de políticas de control de la natalidad, pasando a ser consideradas sujetos de derechos sexuales y reproductivos. Basándose en ello, se recomienda ofrecer información y educación accesible sobre métodos anticonceptivos y

9 La propia OMS, en su estrategia de salud reproductiva para acelerar el avance hacia la consecución de los objetivos y las metas internacionales de desarrollo, se asienta sobre acuerdos y declaraciones mundiales de consenso en materia de derechos humanos, entre los que podemos citar: el derecho de todas las personas a disfrutar del grado máximo de salud que se pueda lograr; el derecho básico de todas las parejas e individuos a decidir libre y responsablemente el número de hijos, el espaciamiento de los nacimientos y el intervalo entre éstos y a disponer de la información y de los medios para ello; el derecho de la mujer a tener control sobre las cuestiones relativas a su sexualidad, incluida su salud sexual y reproductiva, y decidir libremente respecto de esas cuestiones, sin verse sujeta a la coerción, la discriminación y la violencia; el derecho a tener acceso a información pertinente sobre la salud, y el derecho de toda persona a disfrutar de los beneficios del progreso científico y de sus aplicaciones. 
garantizar la elección libre de su uso sin que la discapacidad constituya un objeto de discriminación ${ }^{10}$.

El Comité sobre los Derechos de las Personas con Discapacidad, en su Observación General n. ${ }^{\circ} 3$ dispone que las cuestiones tratadas en el art. 23 tienen importantes repercusiones en otros arts. de la Convención tales como el art. 6 (mujeres con discapacidad), 12 (igual reconocimiento como persona ante la ley), 13 (acceso a la justicia), 15 (protección contra la tortura y otros tratos o penas crueles, inhumanos o degradantes), 16 (protección contra la explotación, la violencia y el abuso), 17 (protección de la integridad personal) y 25 (salud), toda vez que el incumplimiento de las obligaciones positivas contenidas en el art. 23 vulnera también los derechos garantizados en estos arts. ${ }^{11}$ Por ello, la Convención impone a los Estados, "como obligación positiva», suministrar la información precisa sobre reproducción y planificación familiar a las personas con discapacidad, así como una obligación negativa: abstenerse de interferir en el ejercicio de estos derechos.

\section{LA ESTERILIZACIÓN FORZADA O NO CONSENTIDA DESDE UN ENFOQUE DE GÉNERO}

La esterilización se define como «cualquier proceso o acto que produzca en una persona la incapacidad permanente de reproducción sexual $»^{12}$. La esterilización puede llevarse a cabo a través de distintos procedimientos, aunque el más frecuente en las mujeres es la ligadura de trompas, que requiere de intervención quirúrgica. Así, las mujeres pueden optar voluntariamente, tras ser debidamente informadas, por la esterilización como una medida de anticoncepción permanente. Por el contrario, nos encontramos ante una «esterilización forzada o no consentida» cuando este procedimiento se realiza sin el conocimiento o consentimiento de la persona que va a ser sometida a la esterilización. En este caso no atiende a una elección libre de la mujer, sino que la esterilización es decidida por terceras personas que creen saber lo que es mejor para ella y basan su decisión en la discapacidad en lugar de en la salud (Vivas, 2021). Esta práctica se ha llevado a cabo en muchas personas con

10 Respeto de los derechos humanos cuando se proporcionan información y servicios de anticoncepción: Organización Mundial de la Salud (2014). Orientación y recomendaciones. Ginebra. Disponible en: https://bit.ly/3w5NpA5 (consultado el 20 de noviembre de 2020).

11 Observación General n. 3 (2016), sobre las Mujeres y las Nińas con Discapacidad (CRPD/C/GC/3).

12 Mosby's Medical Dictionary (CERMI, 2018). 
discapacidad, especialmente en mujeres y niñas con discapacidad intelectual y psicosocial, vulnerando derechos fundamentales como son el derecho a la libertad, el respeto y la integridad personal. Los ejemplos más representativos son los programas eugenésicos de principios del siglo xx y la corriente de pensamiento neomalthusiana, que pretendía un control de la natalidad. En este sentido, alguna autora sostiene que las esterilizaciones forzadas de los sujetos no aptos para reproducirse han constituido una práctica clínica en el plano de lo que se ha denominado "política científica biomédica», con un objetivo claramente eugenésico (Arnau, 2017).

Sin lugar a dudas, la esterilización forzada representa una manifestación más de violencia contra mujeres y niñas. Además, esta práctica puede tener importantes consecuencias para la salud de las mujeres pues, además de eliminar su capacidad reproductiva, también provoca alteraciones del desarrollo menstrual y hormonal, suprime el deseo sexual y provoca consecuencias en la salud mental, pudiendo presentar las mujeres cuadros de ansiedad y depresión (Casas, 2021). De ahí que el estudio de las esterilizaciones conlleve necesariamente el enfoque de género en la aplicación e interpretación del derecho, por afectar principalmente a mujeres y nińas. Precisamente, la Convención recoge la transversalidad de género en el art. 6, en respuesta a la falta de reconocimiento de los derechos de las mujeres y niñas con discapacidad (Marín, 2021).

El Comité para la Eliminación de la Discriminación contra la Mujer, en su Recomendación n. ${ }^{\circ} 35$ especificó que las violaciones de la salud y de los derechos sexuales y reproductivos de las mujeres, como es la esterilización forzada, es una forma de violencia por razón de género que, «según las circunstancias, pueden constituir tortura o trato cruel, inhumano o degradante» ${ }^{13}$. Sin embargo, el Anteproyecto de Ley Orgánica de Garantía Integral de la Libertad Sexual, en su versión inicial no contempló las esterilizaciones forzadas como una forma más de violencia sexual. Sobre dicha omisión, la Asociación de Mujeres Juezas elaboró un documento de propuestas de enmienda. En concreto, la enmienda n. ${ }^{\circ} 4 \mathrm{al}$ art. 3 del Anteproyecto, que propuso la incorporación de la esterilización forzosa en el ámbito de aplicación de la ley ${ }^{14}$.

13 CEDAW, Recomendación General n. 35 sobre la Violencia por Razón de Género contra la Mujer, de 26 de julio de 2017.

14 Grupo de trabajo de la Asociación de Mujeres Juezas. Propuestas de enmiendas al proyecto de Ley Orgánica de Garantía Integral de la Libertad Sexual, de 22 de marzo de 2021. Disponible en: https://bit.ly/3mC2E0n (consultado el 16 de abril de 2021). Se fundamenta su incorporación "porque es una violencia sexual, ya que condiciona el libre desarrollo de la vida sexual de las mujeres y, por lo tanto, entra de pleno en la definición del apartado 1. Además, para el Convenio de Estambul, junto con el aborto 
En el marco de la Agenda 2030 para el Desarrollo Sostenible también se evidencian las brechas de género (desigualdades en salud, atención sanitaria y violaciones de derechos humanos en entornos sanitarios) a las que se enfrentan las mujeres con discapacidad para disfrutar de su derecho a la salud (Cermi, 2020). Precisamente, entre las categorías de discapacidad y género se pueden identificar aspectos comunes como las relaciones asimétricas de poder, la sexualidad y el «cuerpo marcado» (Díaz, 2005). La Estrategia de la Unión para la Igualdad de Género advierte que la discriminación por razón de género suele combinarse con una discriminación basada en otros rasgos, entre los que se encuentra la discapacidad, lo que provoca una discriminación múltiple. Por ello es esencial que en toda política de igualdad se adopte una perspectiva interseccional horizontal que reconozca y aborde las amenazas múltiples de discriminación ${ }^{15}$. La interseccionalidad conlleva en este caso el análisis de la interconexión entre género y discapacidad que contribuye a la creación y mantenimiento de las desigualdades que sufren las mujeres ( $\mathrm{La}$ Barbera, 2016). En gran medida, las discriminaciones que sufren las mujeres con discapacidad tienen que ver con los estereotipos y prejuicios sobre los que se ha configurado el género y la discapacidad en el imaginario popular: seres inferiores, incapaces, no aptas, «indeseables, asexuales e imposibles como madres» (Balza, 2011).

Pese a que la Convención forma parte de nuestro derecho interno desde el año 2008, en España se han practicado «más de un millar de esterilizaciones forzadas, la mayoría de ellas en mujeres», según la exposición de motivos de la propia LO 2/2020. Práctica que evidencia la negación de la capacidad jurídica de las personas con discapacidad, al tiempo que las priva de derechos fundamentales como es el control de su salud sexual reproductiva, contraviniendo la Convención y los demás tratados de derechos humanos ${ }^{16}$. Dicha práctica ha sido justificada por mitos tales como la incapacidad de las mujeres con discapacidad para ser madres y en las dificultades que puede ocasionar la discapacidad en las funciones reproductivas, atentando directamente contra el art. 23 de la Convención. Así, la discapacidad se ha configurado en torno a una serie de prejuicios que justificaban la esterilización por el bien de la sociedad o la familia. En otros casos, se considera que se actúa en interés de

no consentido, son expresamente violencias de género y sexuales. La ley trata de seguir en todo momento Convenio de Estambul. Debería recoger esto también».

15 Resolución del Parlamento Europeo, de 21 de enero de 2021, sobre la estrategia de la Unión para la igualdad de género (2019/2169 INI).

16 Naciones Unidas. Observación General n. ${ }^{\circ} 1$ (2014) del Comité sobre los Derechos para las Personas con Discapacidad. 
la mujer con discapacidad, con el propósito de protegerla frente al abuso y frente a futuros embarazos no deseados (CERMI, 2018). Así se desprende de una sentencia del Tribunal Constitucional, al considerar que «la esterilización le permite (al incapaz) no estar sometido a una vigilancia constante que podría resultar contraria a su dignidad y a su integridad moral, haciendo posible el ejercicio de su sexualidad ${ }^{17}$. La sentencia afirma que se trata de una medida «beneficiosa para la salud de los deficientes psíquicos graves» ${ }^{18}$. Aunque existiese una especie de "capacímetro" para medir la capacidad de las personas para tener hijos, serviría de poco en el caso de las mujeres con discapacidad. Los estereotipos asociados a la discapacidad entran en el terreno de la subjetividad y las emociones sobre lo que se considera correcto o incorrecto. De ahí que los argumentos para justificar la práctica de la esterilización no consentida sean infundados, respondiendo a estereotipos sociales que estigmatizan a las mujeres con discapacidad (Vivas, 2021). De hecho, los mitos y prejuicios en torno a la asexualidad de las personas con discapacidad ha llevado en muchos casos a que "los profesionales desatiendan situaciones que en otras circunstancias serían tomadas en cuenta sin cuestionamiento» (CERMI, 2020).

Esta percepción negativa, tan arraigada en la cultura popular y jurídica, surge de lo que se ha denominado "capacitismo». Considerado como «un sistema de valores que considera que determinadas características típicas del cuerpo y la mente son fundamentales para vivir una vida que merezca la pena ser vivida» (Montalvo, 2020). El pensamiento "capacitista» considera la discapacidad como una enfermedad o desgracia que conlleva sufrimiento, restando valor a la vida humana (íd.).

En España, la esterilización forzosa ha constituido una grave violación de derechos humanos de las mujeres con discapacidad. Esta práctica ha quedado enmarcada en un modelo paternalista que deniega los derechos humanos sexuales y reproductivos de las mujeres con discapacidad, entre los que se encuentra el derecho a conservar su fertilidad.

\section{ADAPTACIÓN DEL ORDENAMIENTO JURÍDICO ESPAÑOL A LA CONVENCIÓN}

La principal novedad de la Convención no radica en el reconocimiento de nuevos derechos, sino en el mandato expreso a los Estados parte para que supriman de sus regulaciones cualquier forma de discriminación por razón

17 STC 215/1994, de 14 de julio de 1994 (TOL82.620)

18 Íd. 
de la discapacidad. Por consiguiente, el Estado español tiene la obligación de respetar, proteger y hacer efectivo el derecho de todas las personas con discapacidad a la igualdad, absteniéndose de toda acción que suponga cualquier tipo de discriminación. En particular, debe derogar (así lo hace con la LO 2/2020) leyes, reglamentos, costumbres y prácticas existentes que constituyan discriminación contra esas personas. En este contexto de implementación de la Convención al ordenamiento jurídico español se promulga la LO 2/2020, con un único art. que ordena la supresión del párrafo segundo del art. 156 de la Ley Orgánica 10/1995, de 23 de noviembre, del Código Penal. Esta ley constituye un logro impulsado desde la sociedad civil de la discapacidad ${ }^{19}$ y «supone la corrección de una anomalía, de una patología de nuestro ordenamiento jurídico, que castigaba especialmente a las mujeres y adolescentes con discapacidad» (CERMI, 2021).

La redacción del párrafo segundo del art. $156 \mathrm{CP}$ era resultado de una reforma que el legislador llevó a cabo a través de la LO 1/2015, de 30 de marzo, por la que se modificó la Ley Orgánica del Código Penal. Con respecto a la redacción de 1995, el precepto incorporaba novedades importantes con el propósito de adecuar el Código a la Convención. Así, se suprimieron el término «incapaz» y el requisito de que la persona tuviera una grave deficiencia psíquica, al tiempo que se incluyó el carácter permanente de la incapacidad para prestar consentimiento. La esterilización no consentida se contemplaba con carácter excepcional, en un intento por «alejar la sombra del fantasma de las esterilizaciones en masa» de personas con discapacidad como política de Estado (García Álvarez, 2021). El carácter de excepcionalidad hacía preciso acreditar el motivo por el que se acudía a la esterilización no consentida, que debía ser estrictamente necesaria, no habiendo alternativa mejor. También quedaba vinculada a la existencia de un grave conflicto de bienes jurídicos, si bien, en este caso, nos encontrábamos ante la problemática de identificar el bien jurídico con el que podía entrar en colisión la capacidad procreadora de una persona, para que ésta debiera ser sacrificada. Sin embargo, un sector de la doctrina considera que la derogación del párrafo segundo del art. $156 \mathrm{CP}$ no era necesaria para dar cumplimiento a la Convención, pues no contravenía el contenido del art. 23 CDPD. En este sentido, Pastora García Álvarez (2021) sostiene que la previsión contenida en el Código Penal se refería a personas que no podían emitir un consentimiento válido porque carecían de capacidad para

19 Las esterilizaciones forzadas han supuesto una violación grave de los derechos humanos y su abolición ha sido impulsada y promovida gracias al movimiento social de la discapacidad en España. Sobre las trayectorias del movimiento de personas con discapacidad, Gómez (2016). 
comprender. Hasta tal punto que opina que la supresión del párrafo segundo del art. 156 CP era innecesaria y propone la reincorporación de un nuevo párrafo con el siguiente tenor: «no será punible la esterilización acordada por órgano judicial en el caso de personas que de forma permanente no puedan prestar en modo alguno el consentimiento al que se refiere el párrafo anterior, siempre que quede acreditado la necesidad de tal intervención y que la misma redunda en el mayor interés del afectado, todo ello con arreglo a lo establecido en la legislación civil» (García Álvarez, 2021: 83).

Por el contrario, considero que la promulgación de la LO 2/2020 era necesaria y acertada, pues la esterilización coactiva o no consentida no debe tener cabida en el ordenamiento jurídico. En primer lugar, porque tanto en la Convención como en la Ley 8/2021 el legislador ha optado por no diferenciar entre capacidad jurídica y capacidad de obrar precisamente para evitar la negación de la capacidad jurídica de las personas con discapacidad y la posible privación de derechos fundamentales. A esto hay que añadir que el objetivo principal de la reforma civil en materia de discapacidad persigue garantizar el derecho a la toma de decisiones de todas las personas, y en el caso de que existan dificultades para prestar consentimiento se deben garantizar los apoyos precisos. Como se ha mencionado anteriormente, la ley restringe los supuestos de sustitución de la voluntad, de los que debería quedar excluido todo lo relativo a la capacidad reproductora de una persona, aunque esta cuestión será tratada en el apartado del consentimiento por representación.

En definitiva, la esterilización debe enmarcarse en el libre ejercicio de los derechos sexuales y reproductivos, "como elección consciente de un medio anticonceptivo permanente y, por tanto, realizada con pleno conocimiento y con un consentimiento válido del interesado" (Pańos, 2021). Por ello, como no podía ser de otra forma, la LO 2/2020 contempla la remisión del Gobierno a las Cortes Generales de un proyecto de ley de modificación de la Ley Básica Reguladora de la Autonomía del Paciente y de Derechos y Obligaciones en materia de Información y Documentación Clínica (LBAPIDC), y de la Ley Orgánica de Salud Sexual y Reproductiva y de la Interrupción Voluntaria del Embarazo. Esta reforma complementaria es fundamental porque el consentimiento informado es el núcleo en torno al cual gira la relación de los sujetos con el personal sanitario y porque estamos ante algo mucho más relevante que un mero formulario (Cadenas, 2018). Si acudimos a la definición normativa del consentimiento informado, según el art. 3 de la «Ley 41/2002, de 14 de noviembre, básica reguladora de la autonomía del paciente y de derechos y obligaciones en materia de información y documentación clínica», este vendría a ser "la conformidad libre, voluntaria y consciente de un paciente, manifestada en el pleno uso de sus facultades después de recibir la información adecuada, para que tenga lugar una actuación que afecta a su salud». 
En definitiva, no deja de ser un proceso de información dirigido al paciente, que debe reflejarse documentalmente en el historial clínico y que responde al ejercicio de la capacidad legal, a la vez que persigue promover el desarrollo efectivo de los derechos de la ciudadanía. Se puede afirmar que el consentimiento informado constituye una de las manifestaciones más importantes de la autonomía de la voluntad y del reconocimiento de la capacidad jurídica.

Sin embargo, una vez erradicada normativamente la esterilización forzada o no consentida, no significa que en la práctica las mujeres con discapacidad vean garantizado su derecho a decidir libremente si quieren optar por la esterilización como método anticonceptivo permanente ${ }^{20}$. Para ello es preciso que se garantice el consentimiento libre e informado, así como los apoyos para obtener la información necesaria, que, por supuesto, debe ser accesible. Solo de esta forma se respetará el derecho a la salud sexual y reproductiva.

\section{ACCESIBILIDAD A LA INFORMACIÓN DEL CONSENTIMIENTO INFORMADO}

El consentimiento informado se materializa en dos fases: una en la que el personal sanitario ofrece información comprensible y adecuada al usuario en cuestión; y otra en la que este presta el consentimiento. En la primera fase se distingue claramente un elemento intelectual que consiste en comprender la información (Guilarte, 2019). Sin embargo, no siempre esta información atiende a un diseńo universal, siendo inaccesible, con excesiva frecuencia, para las personas con discapacidad. Si la información facilitada por el personal sanitario no se encuentra disponible en un formato accesible o adaptado, no puede garantizarse una información comprensible y adecuada ni la formación libre de la voluntad, constituyendo la inaccesibilidad en sí misma una discriminación por razón de discapacidad. De hecho, la propia Convención incluye entre las formas de discriminación la denegación de ajustes razonables

20 Testimonio de una mujer con síndrome de Asperger que narra cómo cedió, ante la presión que sus padres ejercieron sobre ella, a someterse a una esterilización. El propósito de la intervención era, entre otras cuestiones, evitar transmitir a quienes hubiesen sido sus hijos el síndrome. La mujer relata que la decisión no fue tomada libremente, pese a que gozaba de plena capacidad de obrar: «Por tres razones [...]. Mis padres decían que al ser Asperger no debía tener hijos». Disponible en: https://bit.ly/3CIDSRW (consultado en junio de 2021). "Me ligaron las trompas con 18 ańos. Mi decisión no fue libre», El Pais, 16 de octubre de 2020. Disponible en: https://bit.ly/3CSiQR7 (consultado en junio de 2021). 
(art. 2 CDPD). En la mayoría de los casos el consentimiento informado se reduce a un formulario escrito, a todas luces inaccesible para las personas con discapacidad, especialmente para aquellas que necesitan de apoyo en el acceso a la información y comunicación. En este sentido, la relatora especial de Naciones Unidas (OHCHR, 2018) ha reiterado que la denegación del consentimiento libre e informado es una violación frecuente del derecho a la salud de las personas con discapacidad.

Con el propósito de que las personas con discapacidad puedan vivir en forma independiente y participar plenamente en todos los aspectos de la vida, el tratado incorpora el derecho a la accesibilidad (art. 9 CDPD). Este reconocimiento implica la adopción de medidas para asegurar el acceso de las personas con discapacidad a la información y las comunicaciones y a otros servicios e instalaciones abiertos al público o de uso público. Estas medidas deben incluir la identificación y eliminación de obstáculos y barreras de acceso, aplicándose, entre otros, a los edificios, instalaciones médicas y servicios de información y comunicaciones, incluidos los servicios electrónicos y de emergencia. En el contexto de armonización del ordenamiento interno español, el «Real Decreto Legislativo 1/2013, de 29 de noviembre, por el que se aprueba el Texto refundido de la Ley General de los Derechos de las Personas con Discapacidad y de su Inclusión Social», reguló ampliamente la accesibilidad en el derecho a la vida independiente, contemplando una serie de condiciones básicas para la sociedad de la información, espacios públicos, medios de transporte y Administraciones públicas, pero no así con el derecho a la protección de la salud. La Estrategia Europea para los Derechos de las Personas con Discapacidad 2021-2030 considera la accesibilidad un prerrequisito para la participación plena de las personas con discapacidad ${ }^{21}$. Sin embargo, la Ley Europea de Accesibilidad, que propone el establecimiento de requisitos mínimos de accesibilidad en toda la Unión Europea, se centra únicamente en una serie de productos y servicios digitales, dejando fuera áreas como los servicios de salud, la educación o la vivienda ${ }^{22}$. De ahí que, siguiendo la Estrategia de la Unión 2021-2030 sobre al acceso a la atención de la salud basada en una atención médica inclusiva, accesible y centrada en la persona, resulte fundamental ampliar el alcance de la Ley de Accesibilidad al ámbito sanitario.

21 European Commission (2021). Union of Equality. Strategy for the Rights of Persons with Disabilities 2021-2030. Luxemburg: Publications Office of the European Union.

22 Directiva (UE) 2019/882 del Parlamento Europeo y del Consejo, de 17 de abril de 2019, sobre los requisitos de acceso de productos y servicios. 
Si se acude al Informe de derechos humanos y discapacidad en España (2020), que recoge una serie de denuncias en torno a la vulneración del derecho a la salud $^{23}$, se evidencia la falta de acceso a la información sobre salud sexual y reproductiva, así como a los propios formularios de consentimiento informado (CERMI, 2021). También la Fundación CERMI Mujeres ha denunciado recientemente la invisibilización de la salud de las mujeres con discapacidad, ante la falta de datos de salud y las barreras de acceso al sistema sanitario de las pacientes con discapacidad por falta de accesibilidad no solo en los entornos, sino también en los procesos y en la comunicación. En relación con los derechos de las mujeres y las niñas con discapacidad, ha puesto de manifiesto la incidencia de la pandemia y las múltiples violencias que han interseccionado la vida de las mujeres con discapacidad, incumpliéndose en muchos casos la Convención para la Eliminación de todas las formas de Violencia contra la Mujer y la propia Convención Internacional de los Derechos de las Personas con Discapacidad (CERMI, 2021). Del mismo modo, se han vulnerado los derechos sexuales y reproductivos, al incrementarse las dificultades de acceso a la información para la adopción de decisiones sobre la propia salud sexual y reproductiva. Esta realidad ha de ser puesta en nexo, además de con la Convención, con el mandato contenido en la Ley 33/2011, de 4 de octubre, General de Salud Pública, cuyo art. 6 establece que «todas las personas tienen derecho a que las actuaciones de salud pública se realicen en condiciones de igualdad sin que pueda producirse discriminación por razón de nacimiento, origen racial o étnico, sexo, religión, convicción u opinión, edad, discapacidad, orientación o identidad sexual, enfermedad o cualquier otra condición o circunstancia personal o social».

Precisamente, tras la modificación operada en 2011 de adaptación normativa de la Convención, se ańadió que cuando el paciente fuese una persona con discapacidad se le debían ofrecer las medidas de apoyo pertinentes, incluida la información en formatos accesibles y comprensibles ${ }^{24}$. Para comprobar si esta medida se está aplicando en la práctica, tomaremos como ejemplo un formulario de consentimiento informado de la Comunidad

23 Entre las que cabe mencionar la denuncia de una mujer a la que le denegaron el acceso a una consulta hospitalaria con su perro guía, la falta de intérpretes de lengua de signos en el ámbito sanitario y la ausencia de protocolos de accesibilidad en los centros de salud para personas sordas. También se recogen las demandas de personas sordociegas de una sanidad accesible, sin discriminación por motivo de discapacidad, así como evidencia la merma de los servicios de salud durante la pandemia (CERMI, 2020).

24 Modificación operada por la Ley 26/2011, de 1 de agosto, de adaptación normativa a la Convención Internacional sobre los Derechos de las Personas con Discapacidad. 
Autónoma de Andalucía. En la página web de dicha Administración autonómica se puede acceder al catálogo de formularios de consentimiento informado. Nada más acceder a la página web observamos que los formularios son documentos de texto descargables para su posterior cumplimentación y no ofrecen una alternativa en soporte de voz ni, muchos menos, facilitan el formulario en Braille o en lectura fácil. De entre una extensa lista de posibles intervenciones quirúrgicas en la especialidad de obstetricia-ginecología se encuentra el necesario para la oclusión tubárica bilateral, intervención vulgarmente conocida como ligadura de trompas de Falopio ${ }^{25}$. El formulario indica en qué consiste la intervención: «La oclusión tubárica es un procedimiento quirúrgico que consiste en cortar y ligar las trompas de Falopio para impedir que el óvulo se encuentre con el espermatozoide, y así evitar el embarazo». También informa sobre cómo se llevará a cabo (puede ser laparoscópica, durante una cesárea, vaginal o por histeroscopia, entre otros) y los efectos que le producirá: «contracepción irreversible y permanente en la gran mayoría de los casos (del 99,4\% al 99,8\% de los casos). Es decir, la posibilidad teórica de embarazo después de realizarse la oclusión tubárica es de aproximadamente el $0,5 \%$ de los casos».

El documento hace referencia a la posibilidad de optar a otras alternativas anticonceptivas. Por último, indica los riesgos de la intervención. Tras leer este formulario, no haría falta preguntarse si la información se ha facilitado en un formato accesible y comprensible. Resulta obvio que se trata de un documento inaccesible y que, en consecuencia, discrimina a las personas que no pueden acceder de forma comprensiva a la información que contiene. Sin lugar a dudas, se debe recordar que el consentimiento informado es un "proceso comunicativo y participativo" que tiene lugar en la relación profesional-paciente ${ }^{26}$. Es decir, que más allá del contenido del formulario será el profesional quien explique, con detenimiento, a la persona con discapacidad en qué consiste realmente la intervención y cuáles son los riesgos que puede asumir. ¿Cómo se va a formar libremente la voluntad si la información se ofrece en un formato incomprensible e inaccesible? Resulta difícil entender por qué no se han desarrollado formularios accesibles. Recientemente Plena Inclusión España ha publicado un resumen de la LO 2/2021 en lectura fácil,

25 Formulario de información y consentimiento informado para la oclusión tubárica bilateral (ligadura de trompas de Falopio), elaborado por la Junta de Andalucía según la Orden de 8 de julio de 2009, por la que se dictan instrucciones a los Centros del Sistema Sanitario Público de Andalucía. Disponible en: https://bit.ly/3nPFbbv.

26 Orden de 8 de julio de 2009, por la que se dictan instrucciones a los Centros del Sistema Sanitario Público de Andalucía. 
ejemplo que podría seguirse con la información relativa al consentimiento informado en el ámbito de la salud ${ }^{27}$.

El art. 9 CDPD recoge las medidas que deben adoptar los Estados para garantizar la accesibilidad, como dotar a los edificios e instalaciones de señalización en Braille y formatos de fácil lectura y comprensión, así como ofrecer formas de asistencia humana o animal e intermediarios. También establece la «formación a todas las personas involucradas en los problemas de accesibilidad a que se enfrentan las personas con discapacidad». Por extensión, se considera esencial la formación del personal sanitario en materia de accesibilidad y derechos sexuales y reproductivos de las personas con discapacidad, como pieza fundamental en el proceso comunicativo. De esta forma, se facilitará determinar la información adecuada a las necesidades del paciente, así como a su nivel de comprensión, y, en consecuencia, se garantice que la persona decida libremente. El Comité para los Derechos de las Personas con Discapacidad ha puesto de manifiesto que, con cierta frecuencia, las barreras se deben a la falta de información y de conocimientos técnicos más que a una voluntad consciente de impedir a las personas con discapacidad que accedan a determinados lugares o servicios. Por ello, la formación del personal sanitario debería ir orientada a la eliminación de las barreras y al nuevo modelo social de la discapacidad que desarrolla la Convención. En este sentido, el art. 25 del tratado exige a los profesionales de la salud

que presten a las personas con discapacidad atención de la misma calidad que a las demás personas sobre la base de un consentimiento libre e informado, entre otras formas mediante la sensibilización respecto de los derechos humanos, la dignidad, la autonomía y las necesidades de las personas con discapacidad a través de la capacitación y la promulgación de normas éticas para la atención de la salud en los ámbitos público y privado.

Según la «Recomendación General n. ${ }^{\circ} 35$ sobre la violencia por razón de género contra la mujer» del Comité para la Eliminación de la Discriminación contra la Mujer, España debe responder sobre las iniciativas que se han tomado para capacitar al personal sanitario, en el que queda incluido el que trabaja en la salud sexual y reproductiva. Además, también se contempla una

27 La lectura fácil es una manera de crear documentos que son más fáciles de entender, muy recomendable para las personas con dificultades de comprensión, tengan o no algún tipo de discapacidad intelectual o del desarrollo. Ley que prohíbe la esterilización forzada, Plena Inclusión, 2020. Disponible en: https://bit.ly/2ZUraRP. 
formación obligatoria, periódica y efectiva a los miembros del poder judicial, abogados y funcionarios encargados de hacer cumplir la ley, incluidos el personal médico forense, los legisladores y los profesionales de la salud, en particular en la esfera de la salud sexual y reproductiva, especialmente en los servicios de prevención y tratamiento de las infecciones de transmisión sexual y el VIH, y a todo el personal educativo, social y de bienestar, en particular el que trabaja con mujeres en las instituciones, tales como residencias, centros de asilo y prisiones, a fin de equiparlos para prevenir y combatir debidamente la violencia por razón de género contra la mujer.

Si acudimos a la normativa autonómica andaluza, en concreto a la «Orden SAS/1349/2009, de 6 de mayo, por la que se aprueba y publica el programa formativo de la especialidad de Enfermería Obstétrico-Ginecológica (Matrona)», detectamos que, pese a que las «matronas deben tener una participación activa en los programas de atención a la mujer en todas las etapas de la vida, de salud sexual y reproductiva y de salud maternoinfantil», no se hace una referencia expresa en el perfil competencial a la formación en materia de discapacidad. Sin embargo, dicho perfil sí incorpora que al concluir el programa formativo la matrona debe ser competente y estar capacitada para «asesorar sobre la legislación vigente encaminada a proteger los derechos de la mujer y su familia», lo que incluiría el estudio previo de la Convención. Sin embargo, en el ámbito de la atención primaria-comunitaria, donde la matrona realiza programas de consejo reproductivo, planificación familiar y contracepción, consejo afectivo-sexual o actividades preventivas en salud sexual y reproductiva, no se contempla una remisión expresa a la atención a la discapacidad.

En cuanto al programa formativo de Obstetricia y Ginecología la Orden recoge, entre las habilidades generales, la obtención del consentimiento informado acorde a derecho. Y, con respecto a la relación médico-paciente señala el deber de respetar la autonomía de la paciente y su individualidad. Sin embargo, no especifica entre los conocimientos, habilidades y actitudes el nuevo tratamiento jurídico de la discapacidad, pese a publicarse con posterioridad a la ratificación de la Convención. Por ello, pese a que los derechos a la salud sexual y reproductiva de las mujeres gozan de protección de los instrumentos jurídicos internacionales, no es suficiente con su reconocimiento como derechos humanos, siendo primordial que los recursos sanitarios destinados a atender a las mujeres con discapacidad «tengan en cuenta sus específicas necesidades, así como que se destierren prejuicios trasnochados en torno la sexualidad y reproducción de las mujeres y hombres con discapacidad» (CERMI, 2020: 73). 


\section{ADAPTACIÓN O SUPRESIÓN DEL CONSENTIMIENTO POR REPRESENTACIÓN}

En lo que se refiere al consentimiento informado de las personas con discapacidad, su regulación ha venido distinguiendo los casos en los que la persona tenía dificultad para manifestar el consentimiento o cuya capacidad había sido modificada judicialmente. El Convenio Relativo a los Derechos Humanos y la Biomedicina, anterior a la Convención, regula en el art. 6 la protección de las personas que no tengan capacidad para expresar su consentimiento. A tal efecto establece que solo podrá efectuarse una intervención cuando redunde en su beneficio directo. Para el caso de personas mayores con capacidad modificada judicialmente, requiere la autorización de su representante, autoridad, persona o institución designada por la ley. Sin embargo, «la persona afectada deberá intervenir, en la medida de lo posible, en el procedimiento de autorización» (art. 6). Con una regulación más reciente y anterior también a la Convención, el art. 5.3 de la LBAPIDC establece que cuando el paciente, según el criterio del médico que le asiste, carezca de capacidad para comprender la información, esta «se pondrá en conocimiento de las personas vinculadas a él por razones familiares o de hecho». En el art. 9.3 de la LBAPIDC se fijan los límites del consentimiento informado y del consentimiento por representación cuando el paciente no sea capaz de "tomar decisiones». En el caso de que el paciente carezca de representante legal, el consentimiento será prestado por las personas vinculadas a ella por razones familiares o de hecho. También tendrá lugar el consentimiento por representación cuando el paciente tenga la capacidad modificada y así conste en la sentencia. No obstante, según el art. 9.6 LBAPIDC, en ambos casos «la decisión deberá adoptarse atendiendo siempre al mayor beneficio para la vida o salud del paciente». En cuanto a la prestación del consentimiento, el art. 9.7 LBAPIDC establece que esta será adecuada a las circunstancias y proporcionada a las necesidades que haya que atender, siempre favoreciendo al paciente y respetando su dignidad personal. Por su parte, el art. 9.5 establece que «el paciente participará en la medida de lo posible en la toma de decisiones a lo largo del proceso sanitario».

Tras la modificación operada en 2011 , de adaptación normativa de la Convención ${ }^{28}$, no se modificó el sistema de sustitución por el representante legal, muestra de una situación confusa en la que el reconocimiento de la capacidad de las personas con discapacidad no llega a ser plena y no alcanza

28 Modificación operada por la Ley 26/20111, de 1 de agosto, de adaptación normativa a la Convención Internacional sobre los derechos de las personas con discapacidad. 
a las personas cuya capacidad ha sido modificada judicialmente (Andreu, 2017). También resulta paradójico que el art. 9.3 de la LBAPIDC no haya sido objeto de modificación por la Ley 8/2021, de 2 de junio, por la que se reforma la legislación civil y procesal para el apoyo a las personas con discapacidad en el ejercicio de su capacidad jurídica. En definitiva, la LBAPIDC no es acorde con los postulados de la Convención, pues sustituye la voluntad de la persona para la toma de decisiones. Esto es debido a que vulnera directamente el principio general de respeto a la autonomía individual, la libertad de tomar decisiones así como el reconocimiento de su personalidad jurídica. Por ello, la necesaria adaptación de este art. a la Convención y a la ley 8/2021 discurre por garantizar el respeto a la voluntad de la persona, así como la accesibilidad del propio consentimiento informado.

Según la interpretación que hace el Comité en su Observación General n. ${ }^{\circ}$ 1, las esterilizaciones no consentidas han supuesto la negación de la capacidad jurídica a las personas con discapacidad, por lo que no hay cabida para el consentimiento por representación en el tratamiento médico o las relaciones íntimas ${ }^{29}$. Algunos autores consideran que el consentimiento por representación es un reducto del modelo médico-rehabilitador, pues pretende reemplazar la voluntad de la persona con discapacidad, al considerarla incapaz de tomar sus propias decisiones. En su lugar, correspondería atender al modelo social de la discapacidad, que reconoce la capacidad jurídica y los derechos sexuales y reproductivos de las personas con discapacidad (Hoyos y García, 2017). Además, tal y como sostiene Alba Paños (2021), el consentimiento para la esterilización «es un acto personalísimo de ejercicio de derechos fundamentales que no puede admitir representación, por lo que nadie más que la propia persona afectada podría consentir su esterilización». En este sentido se pronuncia también Judith Solé Resina (2019) proponiendo la supresión del art. 9.3 de la LBAPIDC y la correspondiente eliminación del consentimiento por representación.

Por el contrario, un grupo de autores considera que la Convención "puede terminar dańando precisamente a las personas que pretende ayudar» debido a la interpretación que hace de la misma el Comité de la ONU, impidiendo cualquier intervención involuntaria dirigida a personas con discapacidad (Appelbaum, 2019). Señalan estos estudiosos que en la práctica puede ocurrir que una persona experimente una dificultad seria para tomar decisiones importantes, de ahí la necesidad de reflexionar sobre si las personas que prestan los apoyos deben tener en cuenta exclusivamente su voluntad y preferencias

29 Observación General n.o 1 (2014) del Comité sobre los Derechos de las Personas con Discapacidad. 
o si también puede valorar su interés (Szmukler, 2019). Es cierto que tanto Appelbaum como Szmukler (2019) están pensando en la salud mental, donde las consecuencias clínicas y legales son a veces irreconciliables ${ }^{30}$. En una postura intermedia un sector de la doctrina prioriza la voluntad, preferencias y deseos de las personas con discapacidad, pero propone de forma secundaria el mejor o superior interés (Petit, 2020; Sánchez, 2020). De hecho, Amelia Sánchez (2020) considera que el interés superior también debería constituir un criterio de actuación para la persona que presta el apoyo, en lugar de poner la voluntad como epicentro de la reforma y único criterio, pues esto no siempre es posible. También resalta que la reforma solo contempla aquellos supuestos en los que la persona conserva sus capacidades volitivas e intelectivas en mayor o menor medida, desatendiendo, de esta forma, los supuestos más graves. Sobre el consentimiento por representación en el ámbito de la salud se pronuncia expresamente Cristina Guilarte (2019), que considera que cuando la persona con discapacidad no pueda prestar consentimiento no debe valorarse negativamente el consentimiento por representación si se rodea de las garantías materiales y procesales necesarias. Pese a que las decisiones relativas a la salud reproductiva de la persona corresponden a lo más íntimo del ser humano, no habiendo cabida para la representación legal, la autora considera más oportuna la valoración del discernimiento ad casum para este tipo de decisión de carácter personal (Guilarte, 2018). Así, propone la articulación de un sistema específico para el ámbito de la salud, que permita la toma de decisiones a la persona con discapacidad cuando tenga capacidad suficiente, y la actuación en interés de la misma cuando requiera de apoyos con funciones de representación (Guilarte, 2018). Este nuevo sistema debería contemplar instrumentos para apreciar la capacidad en el caso en concreto, teniendo en cuenta la información facilitada por el personal sanitario, así como escuchar a la persona con discapacidad y a su familia (íd.).

Sin embargo, tal y como se ha expuesto anteriormente, la reforma civil en materia de discapacidad persigue garantizar el derecho a la toma de decisiones de las personas con discapacidad. La ley 8/2021 restringe los supuestos de representación, y ni siquiera en estos casos puede el representante sustituir

30 Steinert expone dos ejemplos clínicos: el de un paciente con depresión delirante y una fuerte intención suicida, y el de una joven con anorexia nerviosa grave cuya vida corre peligro. En los dos supuestos, la preferencia y voluntad de los sujetos pone en peligro sus vidas. De ahí que considere que la interpretación del Comité «invoca una nueva legislación que para estos dos pacientes daría lugar a la consecuencia de la muerte» (Steinert, 2019). 
la voluntad del representado. Cuando no sea posible determinar la voluntad, deseos y preferencias de la persona, quien ejerza las funciones representativas deberá tener en cuenta su trayectoria vital, creencias y valores, así como los factores que ella hubiera tomado en consideración, con el propósito de tomar la decisión que hubiera adoptado en caso de no requerir representación (art. 249 CC). En lo que se refiere a la necesaria reforma de la LBAPIDC, suscribo las propuestas, anteriormente mencionadas, de supresión del art. 9.3 y del consentimiento por representación (Hoyos y García, 2017; Solé, 2109; Paños, 2021).

\section{CONCLUSIONES}

La Convención de Nueva York se ha convertido en el tratado de referencia sobre derechos humanos de las personas con discapacidad. El reconocimiento de la capacidad jurídica universal y de los derechos sexuales y reproductivos de las personas con discapacidad conlleva no solo un cambio de paradigma en el tratamiento jurídico de la discapacidad, sino la necesaria adaptación de nuestro ordenamiento interno a los postulados de la Convención. Las mujeres con discapacidad tienen el derecho a decidir libre y conscientemente si quieren ser madres, el número de hijos que quieren tener, así como disponer de la información y de los medios necesarios para garantizar una salud sexual y reproductiva plena. Con el propósito de erradicar las esterilizaciones forzadas o no consentidas se ha promulgado la LO 2/2020, en un intento de abolir esta práctica y armonizar el ordenamiento interno a la Convención sobre los Derechos de las Personas con Discapacidad, cuyos arts. 12, 15 y 23 eran vulnerados directamente cuando se esterilizaba a una mujer sin su consentimiento. Además, la Ley 8/2021 persigue garantizar el derecho a la toma de decisiones de las personas con discapacidad, restringiendo los supuestos de representación. Incluso en estos supuestos, el único criterio de actuación debe ser el respeto a la voluntad y las preferencias de la persona, no en lo que se suponga que es su interés superior. La aplicación del modelo social de la discapacidad no parece compatible con la representación ni sustitución de la voluntad en la realización de actos jurídicos, sino que promueve un adecuado sistema de apoyos para facilitar la toma de decisiones, que debe situar el interés de la persona con discapacidad detrás de su voluntad, deseos y preferencias, especialmente en lo que a salud sexual y reproductiva se refiere.

La LO 2/2020 constituye un logro histórico para la salud sexual y reproductiva de mujeres y niñas con discapacidad. Sin embargo, para garantizar el ejercicio de la capacidad jurídica, los derechos sexuales y reproductivos y el derecho a la salud de las mujeres con discapacidad, es preciso adaptar 
el tratamiento jurídico del consentimiento informado en el ámbito de la salud. Por ello, se requiere, con cierta urgencia, una nueva regulación de sus límites, regulados en el art. 9 de la LBAPIDC, así como el fortalecimiento de la normativa reguladora en materia de accesibilidad, que garantice el acceso a la información sanitaria. En cuanto al consentimiento por representación, no tiene cabida en el ejercicio de los derechos sexuales y reproductivos desde la perspectiva social de la discapacidad, por lo que en aquellos casos en que no sea posible expresar la voluntad, la persona que preste los apoyos y funciones de representación debe abstenerse de actuar en interés de la persona con discapacidad y de optar por este método de anticoncepción permanente.

También se ha evidenciado que la reforma no debe ser únicamente normativa, pues resulta esencial la formación de los profesionales sanitarios, así como de las propias personas con discapacidad y sus familiares. Las medidas de formación y sensibilización deben luchar contra los estereotipos, los prejuicios y las prácticas nocivas respecto de las personas con discapacidad. Pero también se debe garantizar un personal cualificado y sensibilizado, que disponga de las herramientas necesarias para valorar las necesidades de una persona con discapacidad que pretende someterse a una esterilización.

\section{Bibliografía}

Aguilera Rull, A. y Gili Saldaña, M. (2012). La esterilización forzosa de mujeres romaníes en la República eslovaca: ¿no hay discriminación? InDret. Revista para el Análisis del Derecho, 2, 22. Disponible en: https://doi.org/10.2139/ ssrn.2185343.

Andreu Martínez, M. B. (2017). Autonomía de la mujer, discapacidad y derechos reproductivos. En T. Torres García. Construyendo la igualdad. La feminización del derecho privado (pp. 21-36). Valencia: Tirant lo Blanch.

Appelbaum, P. S. (2019). Salvando la Convención sobre los Derechos de las Personas con Discapacidad de la ONU de sí misma. World Psychiatry. Revista Oficial de la Asociación Mundial de Psiquiatría (WPA), 17 (1), 1-3.

Arnau Ripollés, M. S. (2017). Políticas eugenésicas y derechos reproductivos. Una mirada desde la Bioética (feminista) de/desde la diversidad funcional. Filanderas. Revista Interdisciplinar de Estudios Feministas, 2, 29-51. Disponible en: https://doi.org/10.26754/ojs_filanderas/fil.201722308.

Balza, I. (2011). Crítica feminista de la discapacidad: el monstruo como figura de la vulnerabilidad y exclusión. Dilemata, 3 (7), 57-76.

Brogna, P. (2006). El nuevo paradigma de la discapacidad y el rol de los profesionales de la rehabilitación. Murcia: Universidad de Murcia; El Cisne.

Cadenas Osuna, D. (2018). El consentimiento informado y la responsabilidad médica. Madrid: Boletín Oficial del Estado. 
Cartier, E. (2019). Derecho, (dis)capacidades y sexualidad(es): entre especificades y normalidad. Bioderecho.es, 10.

Casas Planes, M. D. (2021). La mujer con discapacidad y la maternidad y la crianza de los hijos. En especial, la problemática del desamparo (en torno a los cambios jurídicos tras el nuevo paradigma de la Convención de las Personas con Discapacidad. Una experiencia piloto). En G. Tomás y A. Vidu (coords.). Mujer como motor de innovación jurídica y social (pp. 153-182). Valencia: Tirant lo Blanch.

Comité Español de Representantes de Personas con Discapacidad (CERMI) (2018). Poner fin a la esterilización forzosa de las mujeres y niñas con discapacidad. Madrid: Ediciones Cinca.

- (2021). Derechos humanos y discapacidad. Informe España 2020. Madrid: Fundación CERMI.

Comité Español de Representantes de Personas con Discapacidad-Mujeres (CERMI MUJERES) (2020). El derecho a la salud de las mujeres y niñas con discapacidad. Derechos humanos de las mujeres y niñas con discapacidad. Madrid: Fundación CERMI.

Díaz, L. A. y Muñoz, P. (2005). Implicaciones del género y la discapacidad en la construcción de la identidad y la subjetividad. Revista Ciencias Salud Bogotá (Colombia), 3 (2), 156-167.

Elizari Urtasun, L. (2016). Adopción de decisiones en el ámbito clínico por pacientes con discapacidad intelectual, a la luz de la convención sobre los derechos de las personas con discapacidad: autonomía, sistema de apoyos e interés superior de la persona con discapacidad. Derecho Privado y Constitución, 30, 337-369. Disponible en: https://doi.org/10.18042/cepc/dpc.30.08.

European Commission (2021). Union of Equality. Strategy for the Rights of Persons with Disabilities 2021-2030. Luxembourg: Publications Office of the European Union.

García Álvarez, P. (2021). La supresión del segundo párrafo del art. 156 del Código Penal para la erradicación de la esterilización forzada o no consentida de personas con discapacidad, incapacitadas judicialmente. Revista de Derecho y Genoma Humano, Genética, Biotecnología y Medicina Avanzada, 54, 57-84.

García Rubio, M. P. (2021). Contenido y significado general de la reforma civil y procesal en materia de discapacidad. Familia y Sucesiones: Cuaderno Jurídico, $136,45-62$.

Gómez Bernal, V. (2016). La discapacidad organizada: antecedentes y trayectorias del movimiento de personas con discapacidad. Historia Actual Online, 39, 39-52.

Guilarte Martín-Calero, C. (2018). Algunas consideraciones sobre el consentimiento de las personas con discapacidad mental e intelectual. Revista Doctrinal Aranzadi Civil-Mercantil, 11, 141-166.

- (2019). El derecho a la vida familiar de las personas con discapacidad. (El Derecho español a la luz del art. 23 de la Convención de Nueva York). Madrid: Editorial Reus. 
Hoyos Suárez, S. y García Betancurt, J. M. (2017). La esterilización en las personas con discapacidad cognitiva y psicosocial: una perspectiva crítica a la jurisprudencia constitucional. Revista de Derecho Público, 38.

La Barbera, M. C. (2016). Interseccionalidad, un concepto «viajero»: orígenes, desarrollo e implementación en la Unión Europea. Interdisciplina, 4 (8), 105-122. Disponible en: https://doi.org/10.22201/ceiich.24485705e.2016.8.54971.

López Barba, E. (2020). Capacidad jurídica. El art. 12 de la Convención sobre los Derechos de las Personas con Discapacidad y las medidas no discriminatorias de defensa del patrimonio. Madrid: Dykinson. Disponible en: https://doi.org/10.2307/j. ctv17hm8zv.

Manjón Rodríguez, J. B. (2014). Reflexiones biojurídicas sobre la esterilización forzosa de personas con discapacidad psíquica. Derecho y Salud, 24 (1), 144-155.

Marín Cáceres, L. (2021). Formas múltiples e interseccionales de discriminación contra las mujeres y las niñas con discapacidad. En G. Tomás y A. Vidu (coords.). Mujer como motor de innovación jurídica y social (pp. 351-371). Valencia: Tirant lo Blanch.

Montalvo Jääskeläinen, F. y Bellver Capella, V. (2020). Priorizar sin discriminar. La doctrina del Comité de Bioética de España sobre derechos de las personas con discapacidad en un contexto de pandemia. IgualdadES, 2 (3), 313-341. Disponible en: https://doi.org/10.18042/cepc/IgdES.3.02.

Palacios González. M. D. (2019). Discapacidad psíquica y maternidad. La Ley. Derecho de Familia. Revista Juridica Sobre Familia y Menores, 23, 55-62.

Paños Pérez, A. (2021). Esterilización forzosa de mujeres y niñas con discapacidad. En G. Tomás y A. Vidu (coords.). Mujer como motor de innovación jurídica y social (pp. 475-495).Valencia: Tirant lo Blanch.

Petit Sánchez, M. (2020). La adopción de medidas de apoyo para las personas con discapacidad: armonización entre autonomía de la voluntad y el mejor interés. Revista de Derecho Civil, 7 (5), 265-313.

Sánchez Gómez, A. (2020). Hacia un nuevo tratamiento jurídico de la discapacidad: reflexiones a propósito del Proyecto de Ley de 17 de julio de 2020 por la que se reforma la legislación civil y procesal para el apoyo a las personas con discapacidad en el ejercicio de su capacidad jurídica. Revista de Derecho Civil, 7 (5), $385-428$.

Solé Resina, J. (2019). Las esterilizaciones no consentidas de personas con discapacidad. Actualidad Civil, 5.

Steinert, T. (2019). La interpretación de voluntad y preferencias por el Comité de la ONU puede violar los derechos humanos. World Psychiatry. Revista Oficial de la Asociación Mundial de Psiquiatría (WPA), 17 (81), 45.

Szmukler, G. (2019). Capacidad, mejores intereses, voluntad y preferencias y la Convención sobre Derechos de Personas con Discapacidades de las Naciones Unidas. World Psychiatry. Revista Oficial de la Asociación Mundial de Psiquiatría (WPA), 17 (1), 34-41. 
Vázquez Ferreira, M. (2008). La construcción social de la discapacidad: habitus, estereotipos y exclusión social. Revista Critica de Ciencias Sociales y Jurídicas, 17, 221-232.

Vivas Tesón, I. (2021). La esterilización forzosa de mujeres y niñas con discapacidad. En G. Tomás y A. Vidu (coords.). Mujer como motor de innovación juridica y social (pp. 1077-1097). Valencia: Tirant lo Blanch. 